техніка». 2012. Т. 20. № 4. Вип. 16. Т. 2. С. $3-14$.

25. Serdyuk A.I., Protsan Yu.V., Bondarenko S.G. Slurry-propellant rocket propulsion. Eco-safety and new power opportunities. Tests of new propellants (IAC-
2013, C4.3,11). Proc. of 64-th International Astronautical Congress, 23-27 September 2013, Beijing, China. - Beijing, 2013. 9 p.

\title{
РАЗРАБОТКА И ИССЛЕДОВАНИЕ МЕТОДОВ НЕЙТРАЛИЗАЦИИ СОРБЕНТА, ЗАГРЯЗНЕННОГО ПАРАМИ КОМПОНЕНТОВ РАКЕТНОГО ТОПЛИВА
}

\author{
С.А. Кудринский, Г.Л. Поздеев, Л.В. Муравлева, Т.В. Гуназа \\ Государственное предприятие «КБ «Южное», ул. Криворожская, 3, г. Днепр, 49008, \\ Украина, е-mail:info@yuzhnoye.com
}

Розглянуто питання нейтралізації твердих відходів - сорбенту, насиченого парами висококиплячих компонентів ракетного палива (тетраоксид діазоту - окислювач, несиметричний диметилгидразин - пальне). Експериментально перевірено відомі і розроблені оригінальні методи нейтралізації сорбенту, забрудненого парами компонентів ракетного палива. Представлено результати стендових випробувань методів нейтралізації.

Ключові слова: сорбент, нейтралізація, методи нейтралізації, компоненти ракетного палива.

The paper discusses the issues for neutralization of solid waste - sorbent saturated with vapors of highboiling propellants (dinitrogen tetraoxide - oxidizer, nonsymmetrical dymethylhydrazine - fuel). The original methods of neutralizing the sorbent, contaminated with vapors of propellants, have been developed and the known methods have been experimentally checked. The neutralization methods bench test results have been presented.

Keywords: sorbent, neutralization, neutralization methods, propellants.

В работе рассмотрены вопросы нейтрализации твердых отходов - сорбента, насыщеного парами высококипящих компонентов ракетного топлива (тетраоксид диазота - окислитель, несимметричный диметилгидразин - горючее). Экспериментально проверены известные и разработаны оригинальные методы нейтрализации сорбента, загрязненного парами компонентов ракетного топлива. Показаны результаты стендовых испытаний методов нейтрализации. топлива.

Ключевые слова: сорбент, нейтрализация, методы нейтрализации, компоненты ракетного

Введение. В составе систем, агрегатов и средств нейтрализации паров и промстоков токсичных высококипящих компонентов ракетного топлива КРТ (тетраокси диазота - окислитель, несимметричный диметилгидразин - горючее) наземного комплекса применяются «кассетные» и «полочные» фильтрыпоглотители для нейтрализации и обезвреживания паров и дренажных газов КРТ до предельно допустимых концентраций (ПДК). В фильтрахпоглотителях используется наполнитель сорбент, который представляет собой вещество на основе активированного угля, имеющее пористую структуру, обладающую способностью хорошо адсорбировать пары КРТ [1].
Постановка задачи. После насыщения парами КРТ сорбент подлежит нейтрализации и последующей утилизации. Для реализации указанной задачи поставлена цель отработки существующих химических и физических методов нейтрализации сорбента, а также последующей утилизации в условиях космодрома.

Экспериментальная часть. На стендах ГП «КБ «Южное» проводились работы по нейтрализации сорбента, загрязненного окислителем и горючим, с использованием как физического (жидкостного) [2], так и химического методов [3].

$\begin{array}{cr}\text { При нейтрализации } & \text { сорбента, } \\ \text { загрязненного окислителем, } & \text { сорбент }\end{array}$

(C) Кудринский С.А., Поздеев Г.Л., Муравлева Л.В., Гуназа Т.В., 2018 
засыпался в емкость, заливался теплой водой $\left(30-40{ }^{\circ} \mathrm{C}\right)$ и перемешивался в течение 10 мин., после чего замерялась кислотность раствора (водородный показатель $\mathrm{pH})$. Затем добавлялась 3\%-ная или 10\%-ная перекись водорода $\left(\mathrm{H}_{2} \mathrm{O}_{2}\right)$. Этот раствор выдерживался 60 или 30 мин., в зависимости от концентрации используемой перекиси водорода. Далее в раствор добавлялся кристаллический карбонат аммония $\left(\left(\mathrm{NH}_{4}\right) 2 \mathrm{CO}_{3}\right)$ или 5\%ный раствор аммиака, раствор выдерживался в течение 120 мин. Весь процесс проходил с периодическим перемешиванием раствора.

На 100 мл нейтрализуемого сорбента использовалось 600 мл воды, 15 мл перекиси водорода и 36 г карбоната аммония или 380 мл 5\%-го раствора аммиака. Затем раствор сливался через фильтр, а сорбент промывался 2-3 раза водой объемом 600 мл. Перед сливом раствора и после каждой промывки отбиралась проба раствора для проведения анализа на содержание нитритов $\left(\mathrm{NO}_{-2}\right)$ и нитратов (NO-3) (испытания № 1, № 2, № 3).

Также была проведена нейтрализация сорбента только водой (испытания № 4 и № 5) и водой с перекисью водорода (испытания № 6). Результаты анализов приведены в табл. 1.

При нейтрализации сорбента, загрязненого горючим, сорбент засыпался в емкость и заливался раствором уксусной или щавелевой кислоты. Первый образец сорбента обрабатывался 1\%-ным раствором уксусной кислоты, второй образец - 1\%ным щавелевой кислоты, третий и четвертый - 5\%-ным и 10\%-ным раствором уксусной кислоты соответственно. Затем каждый образец выдерживался в растворе кислоты 2 часа с периодическим перемешиванием. После этого раствор сливался, а сорбент промывался водой три раза. После каждой промывки отбиралась проба воды для проведения анализа на содержание в воде горючего. Результаты анализов приведены в табл. 2.

В связи с тем, что концентрация горючего в воде после промывки для всех образцов превышала ПДК, было решено провести еще один цикл нейтрализации с использованием более концентрированного раствора кислоты и с промывкой бо́льшим количеством воды. Первый образец сорбента (100 мл) заливался 5\%-ным раствором уксусной кислоты (600 мл) и промывался 3 раза водой объемом 600 мл. Второй образец сорбента (100 мл) заливался 5\%-ным раствором щавелевой кислоты (700 мл) и промывался 3 раза водой также объемом 700 мл. Третий и четвертый образцы, ввиду незначительного отличия в концентрациях горючего в воде, после промывок были объединены в один образец, который заливался 10\%-ным раствором уксусной кислоты (500 мл) и промывался 3 раза водой объемом 500 мл. После каждой промывки, как и в предыдущем цикле, отбиралась проба воды для проведения анализа на содержание в воде горючего. Результаты анализов приведены в табл. 3.

Анализ полученных результатов (табл. 1, 2, 3) показывает, что применение жидкостного и химического методов для нейтрализации сорбента, загрязненного окислителем, дает возможность достижения ПДК окислителя в промстоках (табл. 1), использование тех же методов для нейтрализации сорбента, загрязненного горючим, является недостаточным для достижения ПДК горючего в промстоках (табл. 2 и 3 ).

Для нейтрализации сорбента, загрязнённого горючим, был разработан оригинальный комбинированный метод, состоящий в том, что сорбент вначале обрабатывается водяным паром с последующей выдержкой, в процессе которой сорбент вакуумируется, затем продувается сжатым газом.

В перфорированный стакан свободно засыпался сорбент (который ранее был подвергнут химической нейтрализации), пар подавался до достижения температуры на поверхности сорбента $80-85{ }^{\circ} \mathrm{C}$, при этом в момент пропарки производился отбор проб конденсата. После пропарки делалась выдержка, в процессе которой сорбент вакуумировался в течении 5 минут при вакууме - 0,095 МПа. 
Таблица 1

\begin{tabular}{|c|c|c|c|c|c|c|c|c|c|c|}
\hline \multirow[b]{2}{*}{$\begin{array}{c}\text { № } \\
\text { испы } \\
\text { тания }\end{array}$} & \multicolumn{6}{|c|}{ Количество исходных и нейтрализующих веществ } & \multirow[b]{2}{*}{$\begin{array}{c}\text { № } \\
\text { промывки }\end{array}$} & \multirow[b]{2}{*}{$\mathrm{pH}$} & \multirow[b]{2}{*}{$\begin{array}{c}\mathrm{NO}_{-}, \\
\text {Мг/л }\end{array}$} & \multirow[b]{2}{*}{$\mathrm{NO}_{3}, \mathrm{Mг} / л$} \\
\hline & $\begin{array}{c}\text { сорбент, } \\
\text { мл }\end{array}$ & $\begin{array}{c}\text { вода,м } \\
\text { л }\end{array}$ & $\begin{array}{c}3 \% \\
\mathrm{H}_{2} \mathrm{O}_{2}, \\
\text { мл }\end{array}$ & $\begin{array}{c}10 \% \\
\mathrm{H}_{2} \mathrm{O}_{2} \\
\text { мЛ }\end{array}$ & $\begin{array}{l}\left(\mathrm{NH}_{4}\right)_{2} \\
\mathrm{CO}_{3}, \Gamma\end{array}$ & \begin{tabular}{|c|} 
5\%-ный \\
раствор \\
аммиака, мл
\end{tabular} & & & & \\
\hline \multirow[t]{4}{*}{1} & \multirow[t]{4}{*}{100} & \multirow[t]{4}{*}{600} & \multirow[t]{4}{*}{15} & \multirow[t]{4}{*}{-} & \multirow[t]{4}{*}{36} & \multirow[t]{4}{*}{-} & 0 & 7 & $9,15^{*}$ & $79,13^{*}$ \\
\hline & & & & & & & 1 & - & - & - \\
\hline & & & & & & & 2 & - & - & - \\
\hline & & & & & & & 3 & - & $\mathbf{0 , 9 5}$ & 29,85 \\
\hline \multirow[t]{3}{*}{2} & \multirow[t]{3}{*}{40} & \multirow[t]{3}{*}{225} & \multirow[t]{3}{*}{-} & \multirow[t]{3}{*}{2} & \multirow[t]{3}{*}{14} & \multirow[t]{3}{*}{-} & 0 & 6,5 & $9,15^{*}$ & $79,13 *$ \\
\hline & & & & & & & 1 & - & - & - \\
\hline & & & & & & & 2 & - & 4,26 & 57,24 \\
\hline \multirow[t]{3}{*}{3} & \multirow[t]{3}{*}{100} & \multirow[t]{3}{*}{600} & \multirow[t]{3}{*}{-} & \multirow[t]{3}{*}{15} & \multirow[t]{3}{*}{-} & \multirow[t]{3}{*}{380} & 0 & 7 & - & - \\
\hline & & & & & & & 1 & - & - & - \\
\hline & & & & & & & 2 & - & 2,44 & 32,96 \\
\hline \multirow[t]{3}{*}{4} & \multirow[t]{3}{*}{100} & \multirow[t]{3}{*}{600} & \multirow[t]{3}{*}{-} & \multirow[t]{3}{*}{-} & \multirow[t]{3}{*}{-} & - & 0 & 6,5 & 16,14 & 84,12 \\
\hline & & & & & & & 1 & - & 5,45 & 70,91 \\
\hline & & & & & & & 2 & - & 1,93 & 31,10 \\
\hline 5 & 100 & 600 & - & - & - & - & 0 & 6 & - & - \\
\hline & & & & & & & 1 & - & - & - \\
\hline & & & & & & & 2 & - & 2,82 & 27,00 \\
\hline 6 & 100 & 600 & - & 15 & - & - & 0 & 6 & - & - \\
\hline & & & & & & & 1 & - & - & - \\
\hline & & & & & & & 2 & - & 3,82 & 25,95 \\
\hline
\end{tabular}

* - содержание нитратов и нитритов в воде, залитой в сорбент после выдержки 10 мин. до добавления в раствор перекиси водорода и кристаллического карбоната аммония.

Продувку сорбента осуществляли сжатым газом с температурой $60{ }^{\circ} \mathrm{C}$ в течение 10 минут, с периодическим отбором проб. Результаты анализов приведены в табл. 4.

Итоги Технология загрязненного данного

исследования. проводилась согласно существующим методикам.
Предельно допустимое содержание в воде нитритов - 3,3 мг/л; нитратов 45 мг/л.

При испытаниях №№ 1-3, в связи с использованием при нейтрализации сорбента раствора аммиака или карбоната аммония, раствор имел яркий бирюзовоголубой цвет, что не дает возможности определить в нем содержание нитратов и нитритов.

Таблица 2

\begin{tabular}{|c|c|c|c|c|c|c|c|c|}
\hline $\begin{array}{c}\text { № } \\
\text { образца }\end{array}$ & $\begin{array}{c}\text { Объем } \\
\text { сорбента } \\
\text { мл }\end{array}$ & $\begin{array}{c}\text { 1\%-ный } \\
\text { раствор } \\
\text { уксусной } \\
\text { кислоты, мл }\end{array}$ & $\begin{array}{c}\text { 1\%-ный } \\
\text { раствор } \\
\text { щавелевой } \\
\text { кислоты, } \\
\text { мл } \\
\end{array}$ & $\begin{array}{c}5 \% \text {-ный } \\
\text { раствор } \\
\text { уксусной } \\
\text { кислоты, мл }\end{array}$ & $\begin{array}{c}\text { 10\%-ный } \\
\text { раствор } \\
\text { уксусной } \\
\text { кислоты, мл }\end{array}$ & $\begin{array}{c}\text { Объем воды } \\
\text { для } \\
\text { промывки, } \\
\text { мл }\end{array}$ & $\begin{array}{c}\text { № } \\
\text { промывки }\end{array}$ & $\begin{array}{c}\text { Концентрация } \\
\text { гептила, мг/л }\end{array}$ \\
\hline \multirow[t]{3}{*}{1} & \multirow[t]{3}{*}{100} & \multirow[t]{3}{*}{150} & \multirow[t]{3}{*}{-} & \multirow[t]{3}{*}{ - } & \multirow[t]{3}{*}{-} & 250 & 1 & 0,30 \\
\hline & & & & & & 250 & 2 & 0,29 \\
\hline & & & & & & 250 & 3 & 0,12 \\
\hline \multirow[t]{3}{*}{2} & \multirow[t]{3}{*}{100} & \multirow[t]{3}{*}{-} & \multirow[t]{3}{*}{150} & \multirow[t]{3}{*}{-} & \multirow[t]{3}{*}{-} & 250 & 1 & 1,77 \\
\hline & & & & & & 250 & 2 & 1,41 \\
\hline & & & & & & 250 & 3 & 1,16 \\
\hline \multirow[t]{3}{*}{3} & \multirow[t]{3}{*}{70} & \multirow[t]{3}{*}{ - } & \multirow[t]{3}{*}{ - } & \multirow[t]{3}{*}{400} & \multirow[t]{3}{*}{-} & 400 & 1 & 2,74 \\
\hline & & & & & & 400 & 2 & 2,72 \\
\hline & & & & & & 400 & 3 & 2,65 \\
\hline \multirow[t]{3}{*}{4} & \multirow[t]{3}{*}{70} & \multirow[t]{3}{*}{ - } & \multirow[t]{3}{*}{ - } & \multirow[t]{3}{*}{-} & \multirow[t]{3}{*}{400} & 400 & 1 & 3,36 \\
\hline & & & & & & 400 & 2 & 2,71 \\
\hline & & & & & & 400 & 3 & 2,45 \\
\hline
\end{tabular}


Таблица 3

\begin{tabular}{|c|c|c|c|c|c|c|c|}
\hline $\begin{array}{c}\text { № } \\
\text { образца }\end{array}$ & $\begin{array}{c}\text { Объем } \\
\text { сорбента, } \\
\text { мл }\end{array}$ & $\begin{array}{c}\text { 5\%-ный } \\
\text { раствор } \\
\text { щавелевой } \\
\text { кислоты, мл }\end{array}$ & $\begin{array}{c}\text { 5\%-ный } \\
\text { раствор } \\
\text { уксусной } \\
\text { кислоты, мЛ }\end{array}$ & $\begin{array}{c}\text { 10\%-ный } \\
\text { раствор } \\
\text { уксусной } \\
\text { кислоты, мЛ }\end{array}$ & \begin{tabular}{|c|} 
Объем воды \\
для \\
промывки, \\
мл \\
\end{tabular} & $\begin{array}{c}\text { № } \\
\text { промывки }\end{array}$ & $\begin{array}{c}\text { Концентрация } \\
\text { гептила, мг/л }\end{array}$ \\
\hline \multirow[t]{3}{*}{1} & \multirow[t]{3}{*}{100} & \multirow[t]{3}{*}{-} & \multirow[t]{3}{*}{600} & \multirow[t]{3}{*}{-} & 600 & 1 & 5,00 \\
\hline & & & & & 600 & 2 & 3,59 \\
\hline & & & & & 600 & 3 & 1,18 \\
\hline \multirow[t]{3}{*}{2} & \multirow[t]{3}{*}{100} & \multirow[t]{3}{*}{700} & \multirow[t]{3}{*}{-} & \multirow[t]{3}{*}{-} & 700 & 1 & 4,77 \\
\hline & & & & & 700 & 2 & 3,56 \\
\hline & & & & & 700 & 3 & 1,68 \\
\hline \multirow[t]{2}{*}{$3(4)$} & \multirow[t]{2}{*}{140} & \multirow[t]{2}{*}{ - } & \multirow[t]{2}{*}{ - } & \multirow[t]{2}{*}{500} & 500 & 1 & 5,60 \\
\hline & & & & & 500 & 2 & 3,10 \\
\hline \multicolumn{2}{|c|}{ Поэтому } & ІЛИз & зора & пробы & раствора & для & анализа \\
\hline
\end{tabular}

содержание нитратов и нитритов проводился после промывки сорбента водой и получения достаточной для проведения анализа прозрачности раствора. При испытании № 1 анализ проводился после третьей промывки, а на испытаниях № 2 и № 3 - после второй промывки. Испытания № 5 и № 6 проводились для подтверждения результатов испытания № 4 на воде и воде с добавлением перекиси водорода соответственно. Так как содержание нитратов и нитритов в воде до и после первой промывки при испытании № 4 значительно превышало ПДК, то идентичных испытаниях № 5 и № 6 отбирались только после второй промывки сорбента. В результате анализа полученных результатов рекомендуется использовать технологический регламент согласно испытаниям 5, 6.

Технология нейтрализации сорбента, загрязненного парами горючего, проводилась согласно существующим методикам.

Предельно допустимая концентрация:

- жидкая среда - 0,02 мг/л;

- $\quad$ газовая среда $-0,1 \mathrm{Mr} / \mathrm{M}^{3}$.

\begin{tabular}{|c|c|c|c|}
\hline № испытания & Наименование операции & Время, ч & Концентрация \\
\hline \multirow[t]{12}{*}{1} & Начало пропарки & $10: 00$ & $4,97 \mathrm{мг/л}$ \\
\hline & \multirow[t]{4}{*}{ Отбор проб (конденсата) } & $10: 10$ & $2,18 \mathrm{мг/л}$ \\
\hline & & $10: 16$ & $1,38 \mathrm{мг/л}$ \\
\hline & & $10: 22$ & 1,14 мГ/л \\
\hline & & $10: 29$ & $0,67 \mathrm{мг/л}$ \\
\hline & Начало вакуумирования & $10: 35$ & - \\
\hline & Окончание вакуумирования & $10: 42$ & - \\
\hline & Отбор проб газовой среды (до продувки) & $10: 46$ & $0,0013 \mathrm{мг} / \mathbf{M}^{3}$ \\
\hline & Начало продувки (сжатым газом) & $10: 50$ & - \\
\hline & \multirow[t]{3}{*}{ Отбор проб (газовой среды) } & $10: 54$ & $0,029 \mathrm{M \Gamma} / \mathbf{M}^{3}$ \\
\hline & & $10: 59$ & $0,0026 \mathrm{Mг} / \mathrm{M}^{3}$ \\
\hline & & 11:08 & 0,0029 мг $/ \mathbf{M}^{3}$ \\
\hline \multirow[t]{12}{*}{2} & Начало пропарки & $11: 05$ & - \\
\hline & \multirow[t]{6}{*}{ Отбор проб (конденсата) } & $11: 07$ & 0,44 мГ/Л \\
\hline & & $11: 24$ & 0,29 мг/л \\
\hline & & $11: 41$ & 0,19 мг/л \\
\hline & & $12: 13$ & $0,2 \mathrm{мг/л}$ \\
\hline & & $12: 31$ & О мг/л \\
\hline & & $12: 35$ & $0,017 \mathbf{M г} / \mathbf{M}^{3}$ \\
\hline & Начало вакуумирования & $12: 37$ & - \\
\hline & Окончание вакуумирования & $13: 25$ & - \\
\hline & Отбор проб газовой среды (до продувки) & $13: 29$ & 0,0013 мг $/ \mathbf{M}^{3}$ \\
\hline & Начало продувки (сжатым газом) & $13: 41$ & - \\
\hline & Отбор проб (газовой среды) & $13: 47$ & $0,01 \mathrm{Mг} / \mathbf{M}^{3}$ \\
\hline
\end{tabular}


Учитывая представленные материалы, можно с уверенностью говорить, что нейтрализацию сорбента, загрязненного окислителем, можно проводить как химическим, так и физическим (жидкостным) методом - промывкой водой. При этом количество образовавшихся промстоков в первом и во втором случае будет практически одинаковым.

Результаты отработки технологии нейтрализации сорбента, загрязненного горючим, показали, что использование жидкостного и химического методов, является недостаточным для достижения ПДК (в промстоках) даже после двух циклов нейтрализации (см. табл. 2, 3). Это свидетельствует о том, что значительное количество горючего проникло достаточно глубоко внутрь структуры гранул сорбента.

Применение комбинированного метода на основе физических процедур позволило обеспечить высокое качество нейтрализации сорбента, загрязненного горючим. Это обусловлено тем, что использование водяного пара позволяет интенсивно удалять продукты химической нейтрализации $\mathrm{c}$ наружной поверхности гранул сорбента и освобождает поры сорбента.

Выводы. Выполненный комплекс работ по нейтрализации сорбента, загрязненного парами окислителя тетраоксид диазота и горючего несиметричный диметилгидразин, показали следующее:

1. Для нейтрализации сорбента, загрязненного парами окислителя, эффективным является жидкостной метод промывка сорбента водой в количестве, превышающем массу сорбента в 6-10 раз, с добавлением в образующейся раствор $5 \%$ перекиси водорода в количестве 10-15 \% от массы сорбента. Достоинством метода является простота и надежность, недостатком - большое количество образующихся слабых промстоков, которые, в свою очередь, требуют утилизации.

2. Для нейтрализации сорбента, загрязненного горючим, использование химического метода нейтрализации растворами уксусной и щавелевой кислоты является неэффективным (ПДК не было достигнуто). Дальнейшая нейтрализация сорбента с использованием оригинального комбинированного метода, включающего обработку сорбента водяным паром с последующим вакуумированием и продувкой сорбента газом, позволила снизить загрязнение сорбента до значений ниже ПДК.

\section{Библиографические ссылки.}

1. Касаткин А.Г. Основные процессы и аппараты химической технологии. Государственное научнотехническое издательство химической литературы. Москва, 1960. 531-545 с.

2. Савенко В.П., Петрусенко Л.И., Федё Е.В. Космическая техника. Ракетное вооружение : сб. науч.-техн. ст. 2017. Вып. 1. Днепр : ГП «КБ «Южное». 115 c.

3. Михальская Л.Л. Отчет о научноисследовательской работе. ООО «Харьковский научный центр военной экологии». № государственной регистрации 0112U005984, 2013. $71 \mathrm{c}$.

Надійшла до редколегіï 06.07.2018р.

\title{
УДК 620.171 .2 \\ ЭКСПЕРИМЕНТАЛЬНЫЕ ИССЛЕДОВАНИЯ СВОЙСТВ УГЛЕРОДНЫХ КОМПОЗИЦИОННЫХ МАТЕРИАЛОВ НА ТРУБЧАТЫХ МОДЕЛЯХ
}

\author{
Т. А. Манько ; И. А. Гусарова ${ }^{2}$; О. П. Роменская ${ }^{2}$; \\ А. А. Самусенко ; И. И. Деревянко ${ }^{2}$ \\ ${ }^{1}$ Днепровский национальный университет имени Олеся Гончара \\ ${ }^{2}$ Государственное предприятие «Конструкторское бюро «Южное» им. М. К. Янгеля»
}

На теперішній час вуглецеві композиційні матеріли широко використовуються в конструкціях космічної техніки. Тенпения по позшипенн спожияання вугпеневого вопокна ппи виготовленні деталей (С Манько Т.А., Гусарова И.А., Роменская О.П., Самусенко А.А., Деревянко И.И., 2018 